\title{
The influence of admixtures on vibration viscosity coefficient of pavement concrete
}

\author{
Jishou $\mathrm{Yu}{ }^{1, a}$ Xiaoping Cai ${ }^{2, b}$ Yong Ge ${ }^{3, c}$ Zhigang Wu ${ }^{4, d}$ \\ ${ }^{1-3}$ School of Transportation Science and Engineering, Harbin Institute of Technology, Harbin \\ 150090, China \\ ${ }^{4}$ ZhongYe research institute of building \\ a hityu@sohu.com ${ }^{\text {b }}$ chaicp@sina.com ${ }^{\mathrm{c}}$ hitbm@163.com ${ }^{\mathrm{d}}$ 388560@qq.com
}

Keywords: Pavement concrete, Vibration viscosity coefficient, Admixture

\begin{abstract}
In this paper, the influences of common admixtures including air entraining agent, superplasticizer, shrinkage-reducing agent, retarder, fly ash and slag on vibration viscosity coefficient of fresh concrete were analyzed. The results showed that the vibration viscosity coefficient of fresh concrete was markedly decreased when using UNF-5 naphthalene formaldehyde sulphonated superplasticizer. When SJ-2 air entraining agent, SZ103 shrinkage-reducing agent, retarder and slag were used, the vibration viscosity coefficient of fresh concrete was also reduced. But when fly ash was added, the vibration viscosity coefficient of fresh concrete was increased.
\end{abstract}

\section{Introduction}

Compared to other materials, cement concrete is suitable for pavement concrete because it has some special properties such as long service life, weather resistant, freezing resistant, wear resistance and anti-slide. Since $80 \mathrm{~s}$, cement concrete road has been rapidly developed. Slipform paving is one of the most advanced construction technology, it is an intelligent and automatic construction technology of pavement concrete. However, research data ${ }^{[1]}$ showed that most advanced slipform pavers imported from developed country are idle because of the disappointed construction quality. The most serious problems are edge collapse and surface voids related to the workability of fresh concrete. And most research results showed that compared to slump, vibration viscosity coefficient is more suitable for evaluating the workability of fresh concrete when slipform paving is used. Both types and dosages of common admixture can influence the vibration viscosity coefficient of fresh concrete. Therefore, in order to guiding construction and improving the engineering quality, the influence law should be studied.

\section{Materials and mix design}

Cement of $\mathrm{P} \cdot \mathrm{O} 42.5$ and class I fly ash were used in all experiments. The fine aggregate used was river sand with the fineness module of 3.4. The coarse aggregate was crushed limestone rock with the maximum grain size of $26.5 \mathrm{~mm}$ and crushing value of $4.5 \%$. The slag is produced by Tong Guang Group with the specific surface area of $4800 \mathrm{~cm}^{2} / \mathrm{g}$. When studied the influence of additives on vibration viscosity coefficient, SJ-2 saponin air entraining agent, UNF-5 naphthalene formaldehyde sulphonated superplasticizer and SZ103 shrinkage-reducing agent were chose. Meanwhile, citric acid and sodium gluconate were chose as retarder.

According to "Test Method of Concrete vibration viscosity coefficient" which can be found in "Technical Specifications of Slipform Construction on Cement Concrete Pavement for Highway" (JTJ/T 037.1-2000), the experimental installation and experimental test method were chose.

The design philosophy was given by "Technical Specifications for Construction of Highway Cement Concrete Pavements" (JTG F30-2003). The base mix proportion is showed in table 1. 
Table1 Mixture proportion of base concrete

\begin{tabular}{ccccccc}
\hline $\begin{array}{c}\text { Strength } \\
\text { standard value } \\
{[\mathrm{MPa}]}\end{array}$ & $W / C$ & $\begin{array}{c}\text { Sand ratio } \\
{[\%]}\end{array}$ & $\begin{array}{c}\text { Water } \\
{\left[\mathrm{kg} / \mathrm{m}^{3}\right]}\end{array}$ & $\begin{array}{c}\text { Cement } \\
{\left[\mathrm{kg} / \mathrm{m}^{3}\right]}\end{array}$ & $\begin{array}{c}\text { Sand } \\
{\left[\mathrm{kg} / \mathrm{m}^{3}\right]}\end{array}$ & $\begin{array}{c}\text { Coarse } \\
\text { aggregate } \\
{\left[\mathrm{kg} / \mathrm{m}^{3}\right]}\end{array}$ \\
\hline 4.0 & 0.40 & 34 & 144 & 360 & 670 & 1300 \\
\hline
\end{tabular}

When studying on the influence of chemical admixtures on vibration viscosity coefficient, $15 \%$ cement was replaced by fly ash, and the substituted coefficient was 1.3. The dosages of superplasticizer were $0.6 \%, 0.8 \%, 1.0 \%$ and $1.2 \%$ respectively, and the dosages of air entraining agent and shrinkage-reducing agent were both from $0.1 \%$ o to $0.6 \%$. When studying on the influence of mineral admixtures on vibration viscosity coefficient, the replacement ratio of fly ash and slag were both $10 \%, 20 \%, 30 \%$ and $40 \%$ respectively. When fly ash and slag were added together, fly ash occupied $30 \%$.

\section{Results and discussions}

Effect of superplasticizer, shrinkage reducing agent and air entraining agent on vibration viscosity coefficient. Figure 1 showed that with the increasing of dosages of superplasticizer, the vibration viscosity coefficient of fresh concrete decreased. It is because of the lubrication action of superplasticizer. When adequate superplasticizer adsorbing on cement powder, there will be a stable solvation water film and steric hindrance will be produced by the film ${ }^{[2]}$. Because of the steric hindrance, the cement powders were separated from each other. At the same time, the slump of concrete also increased with the increasing of superplasticizer. But the most suitable slump for slipform pavers is $15 \sim 40 \mathrm{~mm}^{[3]}$. Therefore the appropriate vibration viscosity coefficient can not be reached by only adjusting the dosages of superplasticizer.

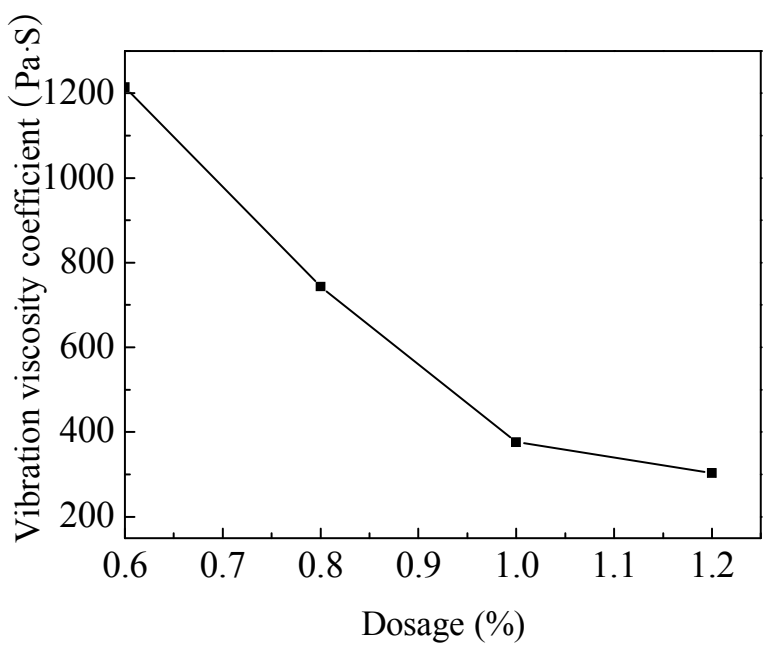

Figure 1 Relationship between dosages of superplasticizer

and vibration viscosity coefficient

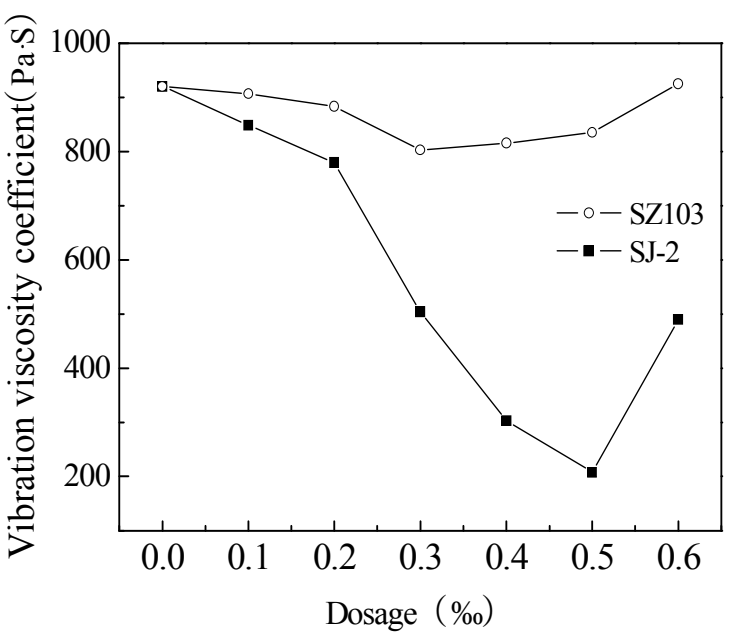

Figure 2 Effect of air-entraining agent and shrinkage reducing agent on vibration viscosity coefficient

It is can be found from figure 2, the vibration viscosity coefficient of fresh concrete was insensitivity with SZ103 shrinkage reducing agent. When the dosages of shrinkage reducing agent were changed from $0.1 \%$ to $0.6 \%$, the vibration viscosity coefficient almost remains unchanged.

Figure 2 also showed that when air entraining agent was used, the vibration viscosity coefficient of fresh concrete was sharply dropped to the lowest point, then it was increased, and the inflection point was $0.5 \%$. There are two mainly effects of air entraining agent. One is "miniature ball 
bearing" effect, the other is surface effect. Numerous minification and individual air bubbles were brought into concrete by air entraining agent. The sliding friction between aggregate was changed into rolling friction by these air bubbles which have the same effect as balls. That means the friction drag becomes lower, and a better liquidity and a lower vibration viscosity coefficient of fresh concrete were reached. On the other hand, some air bubbles were absorbed by the surface of cement powders, which cause an increment of vibration viscosity coefficient. The two effects were concurrent, when the dosage of air entraining was under $0.5 \%$, the "miniature ball bearing" effect was the leading one, otherwise the surface effect was.

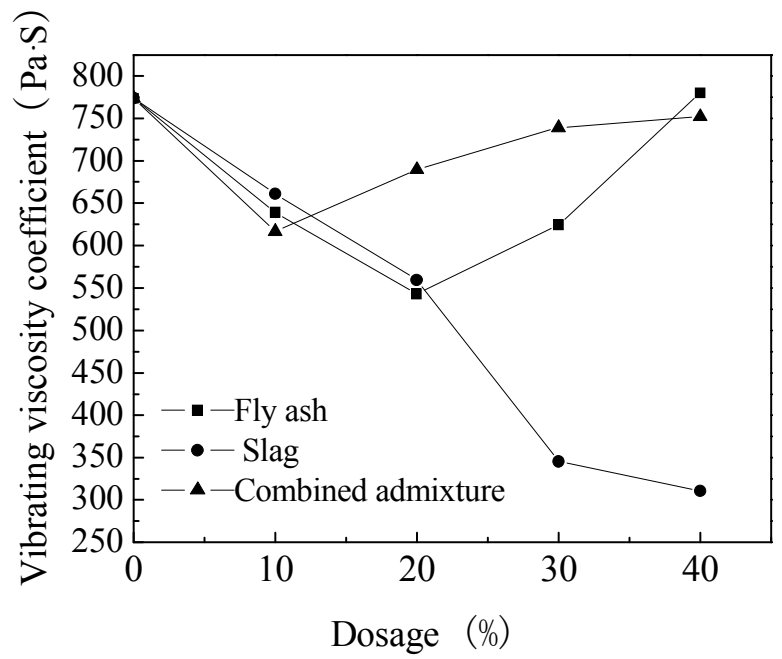

Figure 3 Effect of mineral admixtures on vibration viscosity coefficient

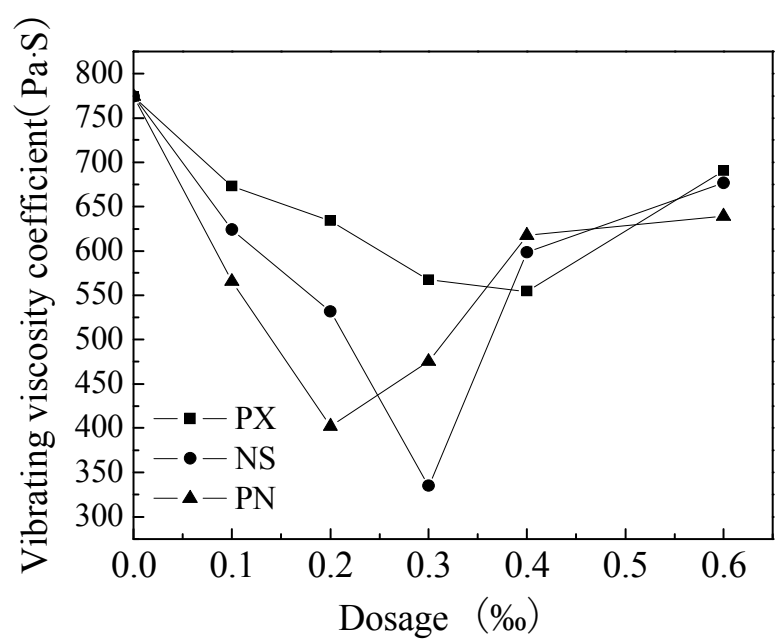

Figure 4 Effect of retarder and cellulose on vibration viscosity coefficient

Effect of mineral admixtures on vibration viscosity coefficient. It is can be seen from figure 3 , when the dosages of slag increased, the vibration viscosity coefficient sharply decreased, because of its higher activity and lower water requirement. When adding fly ash or both of them, the two curves had inflexions, which were $20 \%$ and $10 \%$ respectively. Before the inflexion, vibration viscosity coefficient decreased with the increasing of dosages, and after the inflexion, vibration viscosity coefficient increased with the increasing of dosages. It is because of the effects of fly ash. Three effects of fly ash are volume effect, morphological effect and micro-aggregate effect. The main mineral compositions of fly ash are sponginess vitreous body and aluminosilicate glass microballoon. The sliding friction between binding material powder was changed into rolling friction by these spherical vitreous bodies ${ }^{[5]}$. Secondly, the adsorption force between fly ash and water is less than that between cement and water, and the dispersion of cement powders can be promoted by this character of fly ash. Therefore the vibration viscosity coefficient decreased. On the contrary, because of the low activity, hydration reaction of fly ash was stagnant during the early age, and the volume radio of water and binding materials would be increased. That means the liquidity of concrete mix decreased and the vibration viscosity coefficient increased. Consequently, when the dosages became higher, the vibration viscosity coefficient increased. In a word, the vibration viscosity coefficient decreased because of morphological effect and micro-aggregate effect, and increased because of volume effect. When both fly ash and slag were added, it would be a comprehensive effect.

Effect of other admixture on vibration viscosity coefficient. It is can be seen from figure 4 the vibration viscosity coefficients were decreased in different degree, when cellulose, sodium gluconate and citric acid were added into concrete. Take cellulose as an example, while the dosage 
was $0.4 \%$, the vibration viscosity coefficient of fresh concrete was the lowest one. With the increasing of dosages, the vibration viscosity coefficient increased. However, the decrement causing by cellulose is not enough. Because the demand value of slipform paving is $300 \sim 500 \mathrm{~Pa} \cdot \mathrm{S}$, and the lowest vibration viscosity coefficient was above $550 \mathrm{~Pa} \cdot \mathrm{S}$ when adding cellulose.

Sodium gluconate and citric acid are common retarders of concrete. After adding into concrete, some of them are absorbed by $\mathrm{C}_{3} \mathrm{~A}^{[6]}$, others are dissolved in water and then absorbed by $\mathrm{C}_{3} \mathrm{~S}$. Because of the absorption, the contact between water and cement powder were separated, and the hydration reaction was delayed. Therefore, the workability of concrete can be kept for a long time. When $0.2 \%$ sodium gluconate or $0.3 \%$ citric acid was added, the vibration viscosity coefficient were $400 \mathrm{~Pa} \cdot \mathrm{S}$ and $350 \mathrm{~Pa} \cdot \mathrm{S}$ respectively which were suitable for slipform paving. When the dosages increased, the vibration viscosity coefficient also increased. That means in this research, the best dosages of sodium gluconate and citric acid were around $0.2 \%$ to $0.3 \%$.

\section{Conclusions}

a. The vibration viscosity coefficient of fresh concrete decreased with the increasing dosages of superplasticizer. But the loss of slump was also increased. Therefore the appropriate vibration viscosity coefficient can not be reached by only adjusting superplasticizer.

b. The vibration viscosity coefficient of fresh concrete was insensitivity with SZ103 shrinkage reducing agent, but it was markedly affected by a certain dosage of air entraining agent.

c. With the dosages of slag increased, vibration viscosity coefficient of fresh concrete decreased. When the dosages of fly ash were under $20 \%$, vibration viscosity coefficient of fresh concrete descended, and rose when the dosages were over $20 \%$. The some results were obtained by combined mineral admixtures, and the inflection point was $10 \%$.

d. The vibration viscosity coefficient of fresh concrete markedly decreased when adding retarders like citric acid and sodium gluconate.

\section{References:}

[1] Fu Zhi. Slip-form construction technique of pavement concrete[M]. Bei Jing: People Transport Press, 2000.

[2] Ge Zhaoming. Concrete admixture[M]. Bei Jing: Chemical Industry Press, 2005.

[3] Technical Specifications for Slipform Construction of Highway Cement Pavement Concrete. (JTJ/T037.1-2000).

[4] Xiong Dayu, Wang Xiaohong. Concrete admixture[M]. Bei Jing: Chemical Industry Press, 2002.

[5] Qian Jueshi. Fly ash characteristics and fly ash concrete [M]. Bei Jing: Science press.2002.

[6] Huang Shiyuan, Jiang Jiafen. Modern concrete technology[M]. Shan Xi: Science and Technology Press, 1998. 